\title{
Slit-lamp-adapted optical coherence tomography of pupillary block after Artisan lens implantation for aphakia
}

\author{
Barend Frits Theodorus Hogewind · Thomas Theelen
}

Received: 19 April 2006/Accepted: 9 March 2007Published online: 24 May 2007

(C) Springer Science+Business Media B.V. 2007

\begin{abstract}
We present a report on a patient with acute glaucoma. Slit-lamp-adapted optical coherence tomography (SL-OCT) confirmed a pupillary block due to a claw lens. After laser iridectomy the situation stabilized. Thus, SL-OCT allows non-invasive, high-resolution imaging in acute angle-closure glaucoma and may be helpful with the differential diagnosis of pupillary block glaucoma and the documentation of the surgical result.
\end{abstract}

Keywords Tomography - Optical coherence · Glaucoma · Angle-closure

Slit-lamp-adapted optical coherence tomography (SL-OCT) was recently introduced for anterior segment imaging and goniometry [1]. In the present report we used SL-OCT in the diagnosis and followup of pupillary block glaucoma.

An 80-year-old man presented with acute glaucoma of the right eye after pharmacological mydriasis. Medical history revealed phacoemulsification that had been carried out elsewhere, complicated by intra-vitreal loss of cortex material 2 years ago. $\mathrm{He}$

The authors have no proprietary or financial interest in any research or device presented in this study.

B. F. T. Hogewind $(\bowtie) \cdot$ T. Theelen

Department of Ophthalmology, Radboud University

Medical Centre, Philips van Leydenlaan 15, Nijmegen

6525 EX, The Netherlands

e-mail: f.hogewind@ohk.umcn.nl had been treated by subsequent anterior vitrectomy and Artisan lens implantation.

At presentation at our department, he had an intraocular pressure of $52 \mathrm{mmHg}$. Slit-lamp biomicroscopy showed a peripheral flattened anterior chamber, and no peripheral iridectomy was recognizable. SL-OCT confirmed the absence of peripheral iridectomy, a pupillary block due to the claw lens and bulging of the posterior chamber with secondary angle closure. We measured a central depth of the anterior chamber of $0.91 \mathrm{~mm}$ (Fig. 1A). After laser iridectomy the situation stabilized and the central depth became $1.94 \mathrm{~mm}$ (Fig. 1B).

\section{Comment}

Examination of the anterior segment anatomy is nowadays facilitated by digital devices like the very high frequency ultrasound scan [2]. In this report we used a newly developed method: slit-lamp-adapted optical coherence tomography. SL-OCT allows noninvasive, high-resolution imaging in acute angleclosure glaucoma and may thus be helpful with the differential diagnosis of pupillary block glaucoma and the documentation of the surgical result.

Acknowledgements The instrument for slit-lamp-adapted optical coherence tomography was kindly provided by Medical Workshop, Groningen, Netherlands, under support from the manufacturer, 4-OPTICS, Lübeck, Germany. No financial support was offered from any source. 

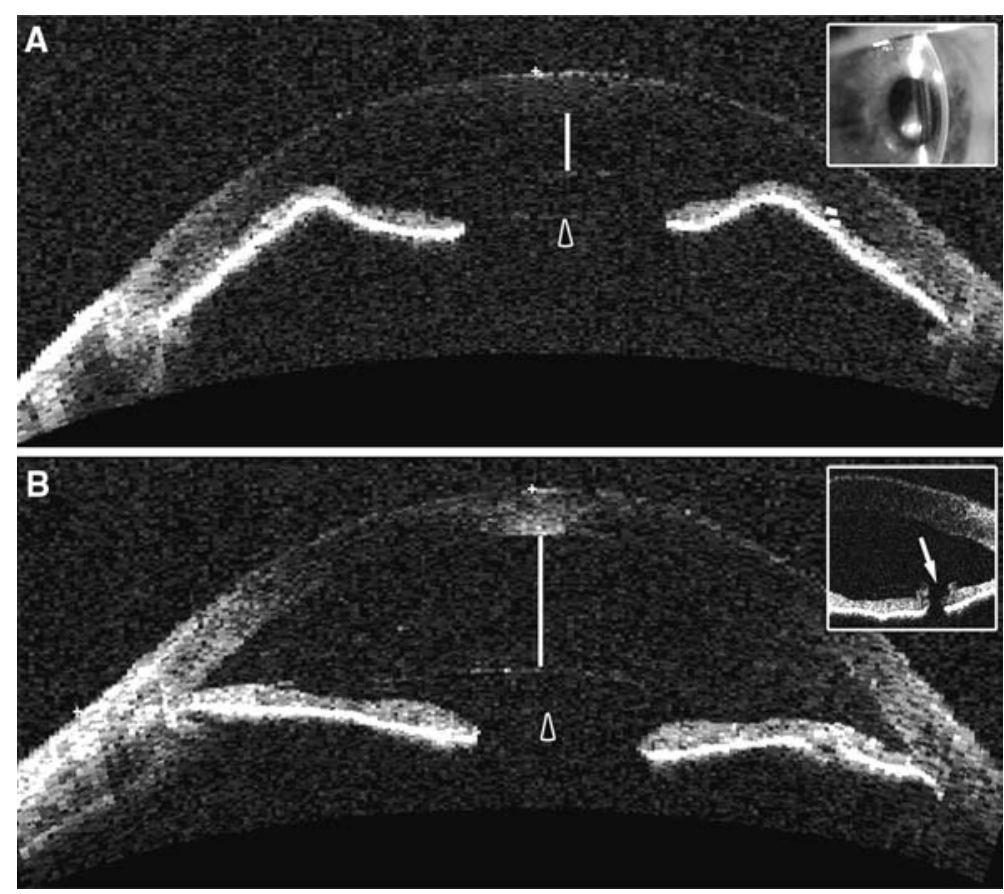

Fig. 1 Panel A shows slit-lamp-adapted optical coherence tomography (15 mm scan) of the patient with acute glaucoma due to the iris-fixed Artisan lens (the inset shows the slit-lamp biomicroscopy). The depth of the anterior chamber is decreased (bar) due to a pupillary block induced by an Artisan lens (arrowhead). Note that the anterior chamber flattening is

\section{References}

1. Wirbelauer C, Karandish A, Haberle H, Pham DT (2005) Noncontact goniometry with optical coherence tomography. Arch Ophthalmol 123:179-185 limited by the haptics of the intraocular lens. Panel $\mathbf{B}$ shows slit-lamp-adapted optical coherence tomography (15 mm scan) after laser iridectomy has deepened the anterior chamber. The depth of the anterior chamber has become normal again. The inset shows a patent iris defect, visible (arrow) on a $7.2 \mathrm{~mm}$ scan

2. Kim DY, Reinstein DZ, Silverman RH, Najafi DJ, Belmont SC, Hatsis AP, Rozakis GW, Coleman DJ (1998) Very high frequency ultrasound analysis of a new phakic posterior chamber intraocular lens in situ. Am J Ophthalmol 123:725729 